Research Trainee

\title{
Walking on Our Lands Again: Turning to Culturally Important Plants and Indigenous Conceptualizations of Health in a Time of Cultural and Political Resurgence
}

\section{Leigh Joseph/styawat}

\section{A R T ICLE INFO}

Keywords:

Ethnobotany

Plants

Indigenous health

https://doi.org/10.32799/ijih.v16i1.33205

A UTHOR INFO

\begin{abstract}
A B S T R A C T
We are in a time of Indigenous cultural-political resurgence in Canada (Coulthard, 2014; Manuel, 2017; Simpson, 2017; Talaga, 2018). Increasingly, Indigenous Peoples are finding renewed strength, pride, and grounding through cultural practice and the reestablishment of connection to the land. Included in this resurgence are the relationships between people and plants. When we practise our ancestral relationships with our plant relatives, we heal and strengthen ourselves. The depth of connection to place, to ancestors, and to our own mindful presence is amplified when we partake in millennia-old practices of plant cultivation, stewardship, and the integration of plant foods and medicines into our bodies. This time of resurgence emerges from generations of Indigenous Peoples suffering devastating violence, losses, and trauma as a result of colonization. In this paper I address the role that rebuilding Indigenous plant relationships plays in addressing colonial impacts on Indigenous health and in supporting Indigenous cultural and political resurgence. I also put forth Indigenized models for understanding colonial impacts on health and discuss culturally rooted conceptualizations of health that address these impacts from an Indigenous point of view. Finally, I propose a set of guidelines to consider for conducting respectful ethnobotanical research within Indigenous communities. This paper is borne out of a desire for deeper critical engagement with the intersections between colonial history, intergenerational trauma, and Indigenous plant knowledge. Furthermore, this paper acknowledges the strength and resilience of Indigenous Peoples in the face of historical injustice.
\end{abstract}

Leigh Joseph/styawat, School of Environmental Studies, University of Victoria, Victoria, British Columbia, Canada. Email: leighjennyjoseph@gmail.com 


\section{Acknowledgements}

I acknowledge the cultural teachers that have guided me on my path to reconnecting with our plant relatives. I also acknowledge my ancestors who fought to carry this knowledge forward so that it can live on in myself and others who are drawn to the relationships with our plant foods, medicines, and materials.

\section{Introduction}

The colonial project in Canada has led directly to the loss of access to land, loss of culturally important foods and medicines, loss of spiritually and culturally important places, and the demonization and criminalization of Indigenous language and ceremony (Armstrong \& McAlvay, 2019; Coulthard, 2014; Elliott, 2019; Geddes, 2017; Maracle, 2017; Paradies, 2016; Regan, 2010; Simpson, 2014, 2017; Talaga, 2018). The intentional separation of Indigenous bodies from the land served the purpose of disenfranchising people and removing them from their source of power, strength, health, and well-being (Coulthard, 2014; Estes, 2019; Simpson 2017).

These impacts have directly affected Indigenous health in Canada. In this age of reconciliation and decolonization, all Canadians have a shared responsibility to educate themselves on colonial history and the ongoing impacts and legacies for Indigenous Peoples in Canada (Truth and Reconciliation Commission of Canada, 2015).

Current Indigenous cultural-political resurgence is a testament to the generations who fought to hold on to pieces of culture, language, and integrity in order to offer future generations the opportunity to move toward renewed health, connection to the land, and cultural identity (Estes, 2019; Simpson, 2017; Talaga, 2018; Turner et al., 2008).

\section{My Story}

I feel it is important to share some context on my positionality as the author of this paper. My ancestral name is styawat. I am a member of the Skwwwú7mesh (Squamish) First Nation on my father's side and from English and Sephardic Jewish ancestry on my mother's side. I was raised primarily with my Coast Salish heritage. One of the most powerful ways I have found to connect to culture and contribute to community has been through my academic studies in the field of ethnobotany, the study of the interrelationships between people and plants.

My studies have been shaped, to a large degree, by my experiences with intergenerational trauma. Through my academic pursuits I have found a path to cultural renewal and healing. I attribute my personal healing to the resilience and strength of my family, many of whom survived unimaginable traumas and losses. My story is part of a continuum along with a vast majority of Indigenous people in this country who are working through the impacts of intergenerational trauma (Elliott, 2019; Lafferty, 2018; Simpson, 2017). The struggles and dysfunction within my family history are in direct response to the state-sanctioned racism and violence that was foundational to residential schools and colonization in Canada. I share this personal context as a call to action to educate ourselves as a society about the colonial history in 
Canada, and how it affects individuals as well as communities, so that we, as researchers, might better understand our indirect roles in upholding racist or discriminatory ideologies and constructs (DiAngelo, 2018; Maracle, 2017; McIntosh, 1988; Regan, 2010).

\section{Methods}

\section{Being Held by the Land}

When I am out harvesting on the land, I am completely present in my body, mind, and spirit. I am partaking in an activity that my ancestors have practised since the beginning of time, and when my children are with me we are sharing ancestral knowledge. The act of harvesting connects me to plants, to the land on which I stand, and to my own heart and mind. I have been taught to introduce myself properly to the land on which I travel and to the plants I am working with. This means considering ancestors who are ever-present. I've been taught to explain where my family line comes from, state who my parents and grandparents are, and show respect for those who have walked before me. This practice serves to create a deeper connection with place, recalling that your family has known the same estuaries, forests, and mountains since time before memory. I believe a deep layer of Indigenous plant knowledge and practice is the innate memory that lives within the spirit and body, that recalls the act of going out on the land to cultivate, harvest, transplant, burn, gather as family, and nourish oneself. I term this ancestral memory. I've felt this as I've harvested and as I've developed my own relationships with Indigenous plants. Developing a feeling of ease on the land takes time and experience. The belief in the presence of ancestors on the land can help facilitate the feeling of ease, belonging, and being at home in natural spaces.

When I teach about plants in Indigenous community, I start by asking people to remember a time when they first learned about a culturally important plant. Or I ask them to recall an important person in their lives who may have taught them about plants. This starts with the seed of a memory, a particular colour, smell, texture, or place that transports them to memories of shared time with family out on the land. The beauty of Indigenous connection to the land through plants is that it is rooted in context, story, specific locality, and loved ones (Geniusz, 2015; Kimmerer, 2013; Simpson, 2017; Turner \& Turner, 2008; Turner, 2014a; Turner 2014b). Beginning a discussion from this place of personal history, and within cultural context, immediately prioritizes the participant by starting from a place that is meaningful to them.

\section{Turning to Teachings From Our Plant Relatives}

It is generally agreed that plants connect Indigenous people to place in very specific and meaningful ways (Basso; 1996; Corntassel \& Bryce; 2012; Cruikshank, 1991, 2007; Cuerrier et al., 2015). Prior to European contact, Indigenous Peoples in Canada relied on their ancestral territories for food, medicine, and the material resources necessary to thrive, both physically and spiritually. "Our food is our medicine" is a phrase commonly heard in Indigenous communities indicating the extent to which culturally important plants are intertwined with the concept of health. Plant-focused cultural practices begin with respectful awareness of a plant relative. 
Where does it grow? When does it bloom? How can it be harvested respectfully and sustainably? What can be done to ensure its viability through propagation, such as root division, seed collecting, stem cuttings, and activities including weeding, pruning, and prescribed burning? What can be done to protect and nurture the place where it grows and reproduces? Kuhnlein and Receveur (1996), in their examination of the loss of traditional food systems, emphasize that

this is a loss of food use as well as a loss of the knowledge required to recognize, harvest, prepare, and enjoy traditional indigenous food resources. It is also a loss of knowledge to all humankind. The consequences of this loss to indigenous peoples are recognized not only culturally, but as a corollary to a variety of chronic diseases that have food and compromised nutritional status within their etiology. (p. 432)

\section{Critical Reflections on Ethnobotany}

The majority of ethnobotanical research in Canada to date has been conducted from a Western European viewpoint and carried out by non-Indigenous academics. Though there exists a history of meaningful collaboration between ethnobotanists and Indigenous communities, it is important to be mindful that inherent power differentials continue to exist between researchers and Indigenous people. These power differentials are grounded in the colonial constructs which Western academic institutions are largely built on. These are factors that can lead to polarization between Indigenous ways of knowing and ways in which ethnobotanical research is conceived and carried out (Battiste, 2013; de Leeuw et al., 2012; Gaudry, 2015; Thomas, 2015; Wilson, 2008). The original definition of ethnobotany coined by John Harshberger in 1896 - "the study of the plant use by primitive peoples"- demonstrates the direct colonial underpinnings of the genesis of this field (Fuller, 2013).

Indigenous relationships with plants are an ancient and integral part of the cultural fabric for Indigenous Peoples. These relationships with plant relatives help shape Indigenous worldviews (Geniusz, 2015; Kimmerer, 2013; Simpson, 2017; Turner, 2005). Ethnobotanists carry a responsibility to ensure that they are considering the impacts of their research on the lives and well-being of the people and the plants that they work with. There is always room for further learning and the development of a deeper understanding of the colonial impacts and ongoing issues affecting Indigenous communities in Canada. Ethnobotanists are well situated to step into purposeful relationships with the communities they work with. An important starting place is to take a critical look at our own self-awareness and make continued efforts to work in the most respectful and informed ways possible.

\section{Introducing an Indigenous Model for Colonial Impacts on Cultural Knowledge}

I propose the following "Indigenized" model as a way to conceptualize the impact of colonization on cultural knowledge, specifically with respect to knowledge about plants and the way that plants bind people to the land both physically and spiritually. I have chosen to approach this model from my positionality as a Skwwwú7mesh woman; however, this model can be readily adapted to other Indigenous communities. I use the Skw xwwú7mesh sníchim (Squamish language) to orient this model in keeping with an Indigenous worldview: skwálwen translates 
approximately to "spiritual heart," temíxw to "land," stelmexw to "people," and spénem to "plants." In each of these categories I show, first, the "gift" that, for example, plants make in terms of nourishment and well-being, followed by the "impact" of colonial disruption on these gifts, such as loss of habitat and negative changes in diet. As shown in Figure 1, Indigenous health is directly linked to the land, culture, and spirituality. This figure is intended to be illustrative rather than comprehensive; the idea is to highlight the impact of colonization on a number of aspects of Indigenous culture, and to demonstrate that healing is conceptualized in terms of interconnectedness. 


\section{Figure 1}

Indigenous Cultural and Political Resurgence Depends on Spiritual and Physical Connections Among Land, People, Plant Relatives, and Heart/Spirit

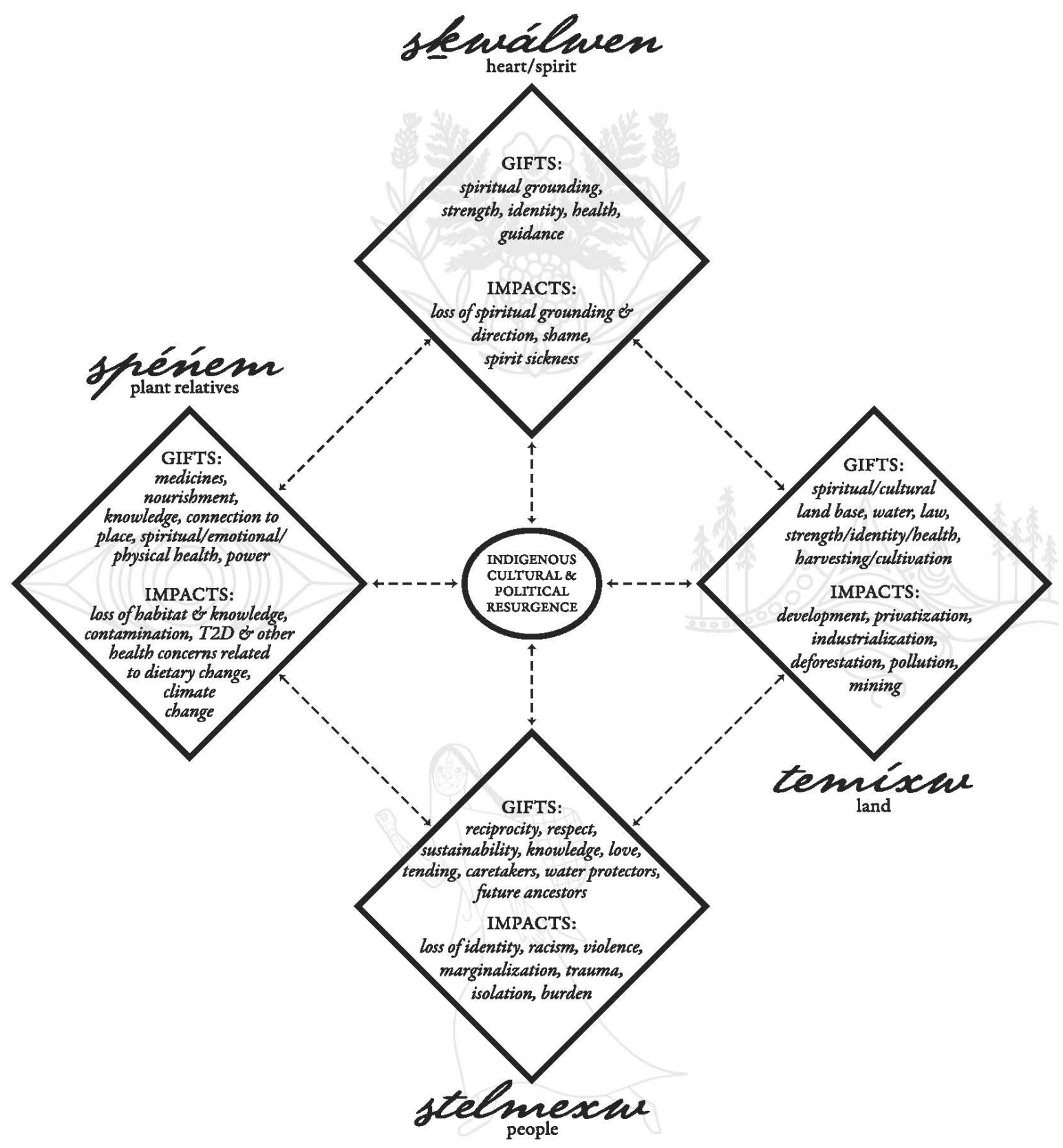




\section{Indigenized Plant-Based Model for Conceptualization of Health}

Indigenous health and well-being are frequently conceptualized as part of a greater whole, in the sense that wellness can only be achieved by ensuring that the interrelated parts are connected: culture, language, spirituality, and the cultural practices that keep the connections animated.

For me the Squamish conceptualization of health, from a plant-based perspective, invokes the image of the wild rose — kalkáy—which functions as a model for seeing health through an ethnobotanical lens. I chose to use kalkáy as a basis on which to develop my model given its cultural importance. The rosehips (fruit), petals, young leaves, and peeled shoots can all be eaten and utilized as medicine. It is a plant that represents the idea of interconnectedness of plant medicines, food plants, and health. I developed this model in collaboration with an Indigenous artist as a way to ground the model with respect to the Indigenous worldview. The centre of the plant represents the idea that good health requires a number of connected elements - which are depicted here as petals - each referring to a culturally grounded requirement for health from an Indigenous viewpoint. 


\section{Figure 2}

The kalkáy (Wild Rose): An Indigenous Conceptualization of the Social and Cultural Determinants of Health, Emphasizing the Layered and Interconnected Nature of the Parts That Make the Whole

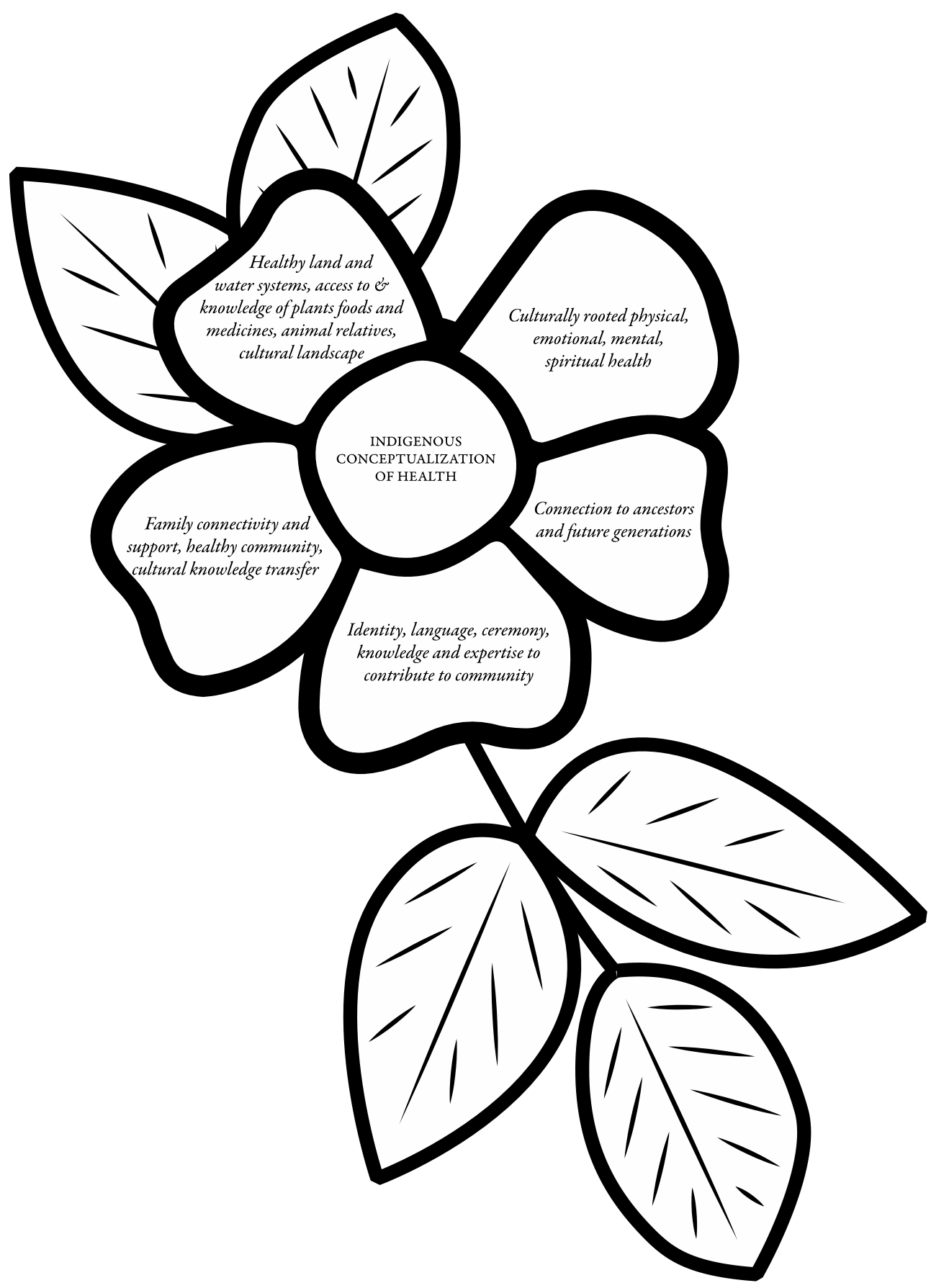

Note: Artwork by Salish artist Ocean Hyland, printed with permission 


\section{Discussion}

\section{Anticolonial and Decolonizing Approaches in Plant-Related Research and Programs}

Historically, research has been used as a tool to, knowingly or unknowingly, dehumanize and disempower Indigenous Peoples and maintain their status as other. How do we then decolonize research within an institution that is inherently colonial in nature? One path forward necessitates that Indigenous people lend their voices and perspectives to "re-storying" dominant Western history - that is, to provide alternative histories from non-European perspectives, thereby allowing Indigenous people to move forward in alternative ways and look toward alternative futures (Corntassel et al., 2009).

\section{Know where we are going by knowing where we have come from.}

As Indigenous people and communities heal from the trauma inflicted by colonization, more and more individuals are contributing their voices and perspectives to the question of change that needs to be made on many fronts, including the way in which research is conceptualized and carried out. Leanne Simpson (2004) proposes that

academics who are to be true allies to Indigenous Peoples in the protection of our knowledge must be willing to step outside of their privileged position and challenge research that conforms to the guidelines outlined by the colonial power structure and root their work in the politics of decolonization and anticolonialism. (p. 381)

Similarly, Linda Tuhiwai Smith (2012) outlines an anticolonial and decolonized approach to research that focuses on the central goal of self-determination, one that recognizes the need for healing, decolonization, transformation, and mobilization of Indigenous Peoples.

\section{Indigenous Plant Relationships as Radical Resurgence}

I propose that the process of revitalizing Indigenous land-based practices, such as cultivation, harvesting, and stewardship, is an act of radical resurgence, and thereby also a means of resistance. The very act of cultivating and harvesting plants for food and medicine can be seen as an act of opposition to the colonial apparatus that was once intent on eradicating Indigenous cultures in the name of the colonial project.

Harvesting can be seen as a political act as much as it is a cultural and ceremonial practice. Cultural protocols, such as speaking directly to plant relatives, leaving an offering when harvesting, and attending to teachings that come in the form of dreams and visions, are embedded within Indigenous ways of knowing (Geniusz, 2015; Kimmerer, 2013). Reo (2019) introduces "relational accountability" as a position that will constitute

an ethical guideline for conducting research with Indigenous nation partners, [because it] references the kincentric beliefs among many Indigenous Peoples. It implies that researchers are responsible for nurturing honorable relationships with community collaborators and are accountable to the entirety of the community in which they work, potentially including collaborators' more-than-human network of relations. (p. 66) 


\section{Researching Respectfully and Responsibly with Indigenous Communities}

Thus far, this paper has briefly summarized the historical and ongoing impacts of colonization for Indigenous Peoples in Canada, with attention to the intersection between colonial history and the field of ethnobotany. It is my assertion that ethnobotanists are required to understand the Indigenous context as a first principle, as are scholars engaged with other Indigenous research topics. Part of this process is to endeavour to decolonize thinking and work to stay critically engaged with the subject matter (Bannister, 2018; Ermine, 2000).

\section{We All Have Blind Spots}

Blind spots are the places where it is difficult to identify or recognize our own bias, privilege, and fragility. By identifying our blind spots we can address them through education and self-reflection. The following list is not meant to be comprehensive, but it is a starting point for considering where blind spots may exist.

1. A researcher may assume that Indigenous people are not capable of understanding their research, so they don't conduct meaningful consultation or disseminate their findings.

2. A researcher may not incorporate community interests or priorities into their research because they don't fit with their vision or what they think is best.

3. A researcher may expect Indigenous people to be "on their research/writing/funding schedule" and become upset, judgmental, or critical when that is not the case.

4. A researcher may opt for judgment and condemnation of dysfunction in Indigenous communities instead of taking the time to understand the underlying impacts and issues that have led to such dysfunction. On the inverse, a researcher may not recognize the resiliency and healing taking place within communities.

5. A researcher may end up interrupting or explaining for Elders or community members who they assume don't know the answer if they don't speak or respond quickly enough.

6. A researcher may end up only listening to one person and taking their word to represent the entire community's perspectives.

7. A researcher may try to take ownership over knowledge that is not theirs in order to elevate themselves personally. They may do this by not acknowledging or crediting who or where the knowledge that informs their work comes from.

8. A researcher may not recognize the privilege that they carry and thus miss the opportunity to use that privilege for good.

As educators we need to consider how we create space for inclusivity and equality in our classrooms. The sentiment "you only know what you know" applies to professors, researchers, or teachers who have not experienced racism directly. Educating oneself on the role of racism at an institutional level is an important part of identifying blind spots that may exist in relation to carrying out anticolonial and Indigenized ethnobotanical research. 


\section{Recommendations}

The following are recommendations for working in a respectful and reciprocal way when conducting ethnobotanical research with Indigenous populations:

1. Identify and follow the protocols for the specific Indigenous individual, family, and community you are working with.

2. Understand that your timeline is not necessarily a community priority. Be prepared to balance the necessity of meeting your institutional and funding requirements with the equal necessity of maintaining a respectful engagement with community.

3. Start by listening and developing relationships. Relationship-building requires being present in the community in ways that may also mean offering to help with other, unrelated work that needs doing (e.g., making tea, cutting wood, cleaning the yard, processing food).

4. Develop a relationship with someone in the community who is willing and in a position to give you guidance and act as a point person. Be mindful that the first person to surface isn't necessarily the best fit. Look to Elders, community leaders, and department heads.

5. If you are not sure, ask, especially when it comes to protocol, gift-giving, respectful behaviour, attending ceremonies, or recording information.

6. Have a foundational understanding of the history of the community you are working in and the impacts of colonization. Continue to develop your understanding of the farreaching impact of historical processes. Be aware of current challenges faced by Indigenous people so that you can work in a more engaged and respectful way.

7. Do not publish, present, or in any way share Indigenous knowledge without community consultation and explicit permission.

8. Follow ownership, control, access, and possession (OCAP) ${ }^{1}$ guidelines as a standard when working with Indigenous knowledge. Disseminate your findings in a way that contributes directly to the community you are working with. Always credit individuals for their knowledge and contribution (unless they specify anonymity); recognize that any non-Indigenous scholar is writing from an outsider perspective and that it important to incorporate Indigenous voices and perspectives into your writing and also to consider writing from a place of critical reflection.

9. Be cautious of overburdening individuals or departments within the community you work with. Often the most culturally active people are the busiest. Consider how much energy, time, and space you take away from people and resources that are dedicated to community and remunerate people for their time. Be aware that Elders should be remunerated at a higher rate for their time due to their status within community. Ask if the community has a remuneration structure already in place. If not, co-develop one with the community.

\footnotetext{
${ }^{1}$ Standing for ownership, control, access, and possession, OCAP ${ }^{\circledR}$ is a registered trademark of the First Nations Information Governance Centre (FNIGC; https://fnigc.ca/ocap).
} 
10. Gift-giving and reciprocity is a central teaching across many Indigenous communities. The practices vary but giving back and redistributing wealth in the form of Indigenous foods, plant medicines, or other gifts is deeply appreciated, enacts reciprocity, and honours the mutually beneficial nature of a healthy research relationship.

11. Give back. If your research deals with Indigenous knowledge, culturally important species, or cultural "keystone" places, be sure to share your research privilege and resources by offering opportunities for Indigenous community members to engage with and (re)connect to the subject of your research. This may include capacity building through training community members, and conducting meaningful knowledge translation of practical and tangible results that the community may integrate into programs and decision-making.

\section{Conclusion}

In conclusion, researching and collaborating from a place of respect and reciprocity can help us, as ethnobotanists, learn how our skills and expertise can best contribute to the communities we work with. By taking the time to develop a critical awareness of the extent to which colonization has disrupted and fractured the transmission of Indigenous cultural knowledge, and by becoming aware of our own biases when it comes to our understanding of settler history, ethnobotanists stand to be meaningful allies to the Indigenous communities we work with.

\section{References}

Armstrong, C. G., \& McAlvay, A. C. (2019). Introduction to special section on action ethnobiology. Journal of Ethnobiology, 39(1), 3-13. https://doi.org/10.2993/0278-077139.1 .3

Bannister, K. (2018). From ethical codes to ethics as praxis: An invitation. Ethnobiology Letters 9(1), 13-26. https://doi.org/10.14237/ebl.9.1.2018.1060

Basso, K. H. (1996). Wisdom sits in places: Landscape and language among the Western Apache. University of New Mexico Press.

Battiste, M. (2013). Decolonizing education: Nourishing the learning spirit. Purich Publishing.

Corntassel, J., \& Bryce, C. (2012). Practicing sustainable self-determination: Indigenous approaches to cultural restoration and revitalization. The Brown Journal of World Affairs 18(2), 151-162. https://www.jstor.org/stable/24590870

Corntassel, J., Chaw-win-is, and T'lakwadzi. (2009). Indigenous storytelling, truth-telling, and community approaches to reconciliation. ESC: English Studies in Canada, 35(1), 137159. https://doi.org/10.1353/esc.0.0163

Coulthard, G. S. (2014). Red skin, white masks: Rejecting the colonial politics of recognition. University of Minnesota Press. https://doi.org/10.5749/minnesota/9780816679645.001.0001 
Cruikshank, J. (1991). Life lived like a story: Life stories of three Yukon Native Elders. UBC Press.

Cruikshank, J. (2007). Do glaciers listen? Local knowledge, colonial encounters, and social imagination. UBC Press.

Cuerrier, A., Turner, N. J., Gomes, T. C., Garibaldi, A., \& Downing, A. (2015). Cultural keystone places: Conservation and restoration in cultural landscapes. Journal of Ethnobiology, 35(3), 427-448. https://doi.org/10.2993/0278-0771-35.3.427

de Leeuw, S., Cameron, E. S., \& Greenwood, M. L. (2012). Participatory and community-based research, Indigenous geographies, and the spaces of friendship: A critical engagement. The Canadian Geographer, 56(2), 180-194. https://doi.org/10.1111/j.15410064.2012.00434.x

DiAngelo, R. (2018). White fragility: Why it's so hard for white people to talk about racism. Beacon Press.

Elliott, A. (2019). A mind spread out on the ground. Doubleday.

Ermine, W. J. (2000). A critical examination of the ethics in research involving Indigenous Peoples [Master's thesis, University of Saskatchewan]. HARVEST archive. https://harvest.usask.ca/bitstream/handle/10388/etd-01182007133515/Ermine_john_2000.pdf

Estes, N. (2019). Our history is the future: Standing Rock versus the Dakota Access Pipeline, and the long tradition of Indigenous resistance. Verso.

Fuller, R. J. M. 2013. "Ethnobotany: major developments of a discipline abroad, reflected in New Zealand." New Zealand Journal of Botany 51 (2):116-138. doi: 10.1080/0028825X.2013.778298.

Gaudry, A. (2015). Researching the resurgence: Insurgent research and community-engaged methodologies in 21 st-century academic inquiry. In S. Strega \& L. Brown (Eds.), Research as resistance: Revisiting critical, Indigenous, and anti-oppressive approaches (2nd ed., pp. 243-263). Canadian Scholars' Press.

Geddes, G. (2017). Medicine unbundled: A journey through the minefields of Indigenous health care. Heritage House.

Geniusz, M. S. (2015). Plants have so much to give us, all we have to do is ask: Anishinaabe botanical teachings. University of Minnesota Press.

Kimmerer, R. W. (2013). Braiding sweetgrass: Indigenous wisdom, scientific knowledge and the teachings of plants. Milkweed Editions.

Kuhnlein, H. V., \& Receveur, O. (1996). Dietary change and traditional food systems of Indigenous Peoples. Annual Review of Nutrition, 16(1), 417-442. https://doi.org/10.1146/annurev.nutr.16.1.417

Lafferty, C. (2018). Northern wildflower: A memoir. Roseway Publishing.

Manuel, A. (2017). The reconciliation manifesto: Recovering the land, rebuilding the economy. James Lorimer and Company. 
Maracle, L. (2017). My conversations with Canadians. BookThug.

McIntosh, P. (1988). White privilege and male privilege: A personal account of coming to see correspondences through work in women's studies (Working Paper 189). Wellesley Centers for Women.

https://www.wcwonline.org/images/pdf/White_Privilege_and_Male_Privilege_Personal_ Account-Peggy_McIntosh.pdf

Paradies, Y. (2016). Colonisation, racism and Indigenous health. Journal of Population Research, 33(1), 83-96. https://doi.org/10.1007/s12546-016-9159-y

Regan, P. (2010). Unsettling the settler within: Indian residential schools, truth telling, and reconciliation in Canada. UBC Press.

Reo, N. J. (2019). Inawendiwin and relational accountability in Anishnaabeg studies: The crux of the biscuit. Journal of Ethnobiology, 39(1), 65-75. https://doi.org/10.2993/0278-077139.1 .65

Simpson, L. B. (2014). Land as pedagogy: Nishnaabeg intelligence and rebellious transformation. Decolonization: Indigeneity, Education \& Society, 3(3), 1-25. https://jps.library.utoronto.ca/index.php/des/issue/view/1584

Simpson, L. B. (2017). As we have always done: Indigenous freedom through radical resistance. University of Minnesota Press. https://doi.org/10.5749/j.ctt1pwt77c.

Simpson, L. B. (2004). Anticolonial strategies for the recovery and maintenance of Indigenous knowledge. American Indian Quarterly, 28(3/4), 373-384. https://doi.org/10.1353/aiq.2004.0107

Smith, L. T. (2012). Decolonizing methodologies: Research and Indigenous Peoples (2nd ed). Zed Books.

Talaga, T. (2018). All our relations: Finding the path forward. House of Anansi Press.

Thomas, R. Qwul'sih'yahmaht. (2015). Honoring the Oral Traditions of the Tat Mustimuxw (Ancestors) Through Storytelling. In Research as Resistance: Revisiting Critical, Indigenous, And Anti-Oppressive Approaches, Brown, S. and Strega, L., eds., 177-98. Toronto ON: Canadian Scholars' Press.

Truth and Reconciliation Commission of Canada. (2015). Honouring the truth, reconciling for the future: Summary of the final report of the Truth and Reconciliation Commission of Canada. http://www.trc.ca/assets/pdf/Honouring_the_Truth_Reconciling_for_the_Future_July_23 _2015.pdf

Turner, N. J. (2005). The earth's blanket: Traditional teachings for sustainable living. Douglas $\&$ McIntyre.

Turner, N. J. (2014a). Ancient pathways, ancestral knowledge: Ethnobotany and ecological wisdom of Indigenous Peoples of northwestern North America (Vol. 1). McGill-Queen's University Press. 
Turner, N. J. (2014b). Ancient pathways, ancestral knowledge: Ethnobotany and ecological wisdom of Indigenous Peoples of northwestern North America (Vol. 2). McGill-Queen's University Press.

Turner, N. J., Gregory, R., Brooks, C., Failing, L., \& Satterfield, T. (2008). From invisibility to transparency: Identifying the implications. Ecology and Society, 13(2), Article 7. https://doi.org/10.5751/ES-02405-130207

Turner, N. J., and Turner, K. L. (2008). "Where our Women Used to Get the Food": Cumulative Effects and Loss of Ethnobotanical Knowledge and Practice; Case Study from Coastal British Columbia. Botany 115, 103-115. https://doi.org/10.1139/B07-020

Wilson, S. (2008). Research is ceremony: Indigenous research methods. Fernwood Publishing. 